\begin{tabular}{cc|c}
\hline Tar. Bil. Der. & Journal of Agricultural Sciences \\
& $\begin{array}{c}\text { Dergi web sayfası: } \\
\text { www.agri.ankara.edu.tr/dergi }\end{array}$ & Journal homepage: \\
& www.agri.ankara.edu.tr/journal
\end{tabular}

\title{
Eğirdir Gölü Koruma Zonları CORINE Arazi Kullanım Sınıflaması
}

\author{
Mehmet GENÇER ${ }^{\mathrm{a}}$, Levent BAŞAYIĞ́íT ${ }^{\mathrm{a}}$, Mesut AKGÜL ${ }^{\mathrm{a}}$ \\ ${ }^{a}$ Süleyman Demirel Üniversitesi, Ziraat Fakültesi, Toprak Bilimi ve Bitki Besleme Bölümü, Isparta, TÜRKIYE
}

\section{ESER BİLGÍSİ}

Araștırma Makalesi

DOI: 10.1501/Tarimbil 0000001306

Sorumlu Yazar: Levent BAŞAYİĞİT, E-posta: leventbasayigit@hotmail.com, Tel: +90 (541) 2643155

Geliş Tarihi: 02 Eylül 2013, Düzeltmelerin Gelişi: 29 Kasım 2013, Kabul:19 Şubat 2014

\section{ÖZET}

Bu çalışmada, Eğirdir Gölü çevresi koruma zonları için CORINE arazi kullanım haritasının hazırlanması yer almaktadır. Çalışmada SPOT-4 uydu verisi kullanılmış, kontrollü sınıflama yöntemine göre sınıflandırma yapılmış, sınıflandırılmış veriler üç farklı test alanında kontrol edilmiş ve CORINE arazi kullanım haritası oluşturulmuştur. Üretilen harita, göl kıyısından itibaren 300-1000-2000-5000 m'lik zonlara bölünmüș ve her bir zon münferit olarak irdelenmiştir. Ayrıca üretilen harita, CORINE 2006 haritası ile karşılaştırılmıştır. Çalışma sonunda alanda en yaygın bulunan arazi kullanım türünün sklerofil bitki örtüsü olduğu, en az bulunan arazi kullanım türünün ise maden çıkarım sahalarından oluştuğu belirlenmiştir. Yerleşim alanlarının göl için kritik bölgelerde yoğunlaştığı belirlenmiştir. Türkiye'nin tamamı için hazırlanan CORINE 2006 haritasını güncellenmesi gerektiği sonucuna varılmıştır.

Anahtar Kelimeler: Eğirdir Gölü; Koruma zonu; CORINE; SPOT 4; Coğrafi bilgi sistemleri (CBS)

\section{CORINE Land Use Classification of Eğirdir Lake Protection Zones}

\author{
ARTICLE INFO \\ Research Article \\ Corresponding Author: Levent BAŞAYİĞİT, E-mail: leventbasayigit@hotmail.com, Tel: +90 (541) 2643155 \\ Received: 02 September 2013, Received in Revised Form: 29 November 2013, Accepted: 19 February 2014
}

\begin{abstract}
In this study, the CORINE land use map for protection zones was produced for Eğirdir Lake around. For this purpose, SPOT-4 satellite data was classified by supervised classification method, the classification map was checked in three plots, and CORINE land use map was produced. The map was divided into zones by considering the distance (3001000-2000-5000 meter) from the coastal line of the lake and then the individual zones were examined. In addition this map was compared the map of CORINE 2006. As a result, it was determined that the most common land use type was sclerophyllous vegetation, and the rarest land use type was mineral extraction sites. In addition, the urban areas were located on the critical region of the lake's watershed. As the CORINE map of the study area was compared to that of CORINE 2006 map, there is a need for CORINE 2006 map of Turkey to be updated.
\end{abstract}

Keywords: Eğirdir Lake; Protection zone; CORINE; SPOT-4; Geographic Information System (GIS) 


\section{Giris}

Yeryüzünün temel yaşam desteği olan su günümüzde stratejik bir kaynak olarak nitelendirilmektedir. $\mathrm{Bu}$ nedenle tatlı su kaynakları üzerindeki tasarruf, suyun korunması söz konusu olduğunda, yalnızca suya sahip ülkeleri değil aynı zamanda dünyayı ilgilendirmektedir. $\mathrm{Bu}$ yaklaşım suyun kullanımı ve korunması konularında uluslararası kanunların geliştirilmesi ve uygulanması ile sonuçlanmıştır.

Ülkemizde suların kullanımına yönelik yönetmelikler uluslararası anlaşmalara uygun olarak hazırlanmış ve uygulamaya konulmuştur. Çevre ve Orman Bakanlığınca 31.12.2004 tarihinde yürürlüğe giren "Su Kirliliği Kontrolü Yönetmeliği" ülkemizin yeraltı ve yerüstü su kaynakları potansiyelini korumayı ve en iyi bir biçimde kullanımını sağlamayı, su kirliliğini önlemeyi ve sürdürülebilir kullanım sağlamayı hedeflemiştir. $\mathrm{Bu}$ yönetmelik su ortamlarının kalite sınıflandırmaları ve kullanım amaçlarını, su kalitesinin korunmasına ilişkin planlama esasları ve yasaklarını, atık suların boşaltım ilkelerini ve boşaltım izni esaslarını, atık su altyapı tesisleri ile ilgili esasları ve su kirliliğinin önlenmesi amaciyla yapılacak izleme ve denetleme usul ve esaslarını kapsamaktadır.

Ayrıca, Çevre ve Orman Bakanlığınca hazırlanan ve 18 Şubat 2004 tarihinde yayınlanan "Tarımsal Kaynaklı Nitrat Kirliliğine Karşı Suların Korunması” Yönetmeliği çerçevesinde Gıda Tarım ve Hayvancılık Bakanlığının koordinasyonunda ilgili kuruluşlar tarafindan bütün sularda kirlenmeye karşı genel bir korunma düzeyi sağlamak amacıyla iyi tarım uygulama esasları oluşturmayı amaçlamıştır (AB 2011).

Eğirdir Gölü çevresinde tarım alanlarında uygulanan sulama teknikleri, pestisitler ve kimyasal gübreler, tarımsal, evsel ve endüstriyel atıklar, gereksiz su israfi, toprak erozyonu, kaçak yapılaşma ve nüfus artışı bulunmakta, bu gerçekler gölü tehlikeye atan en önemli unsurlar olarak karşımıza çıkmaktadır. Bu sorunun çözümünde temel yaklaşım iyi bir planlamanın yapılmasıdır. Planlamada ise ilk aşama arazi envanterlerinin belirlenmesi ve şimdiki kullanım durumunun tespitidir. Arazi kullanım türlerinin belirlenmesinde ise uydu görüntülerinin kullanımı standart bir yöntem haline gelmiştir. CORINE, arazi kullanım türlerinin belirlenmesinde uzaktan algılama görüntülerinin kullanımı birçok ülke tarafindan uygulanan ve kabul gören bir metottur. $\mathrm{Bu}$ metot topluluğun çevre politikasının saptanması, politikaların doğruluğunun kontrolü, topluluğun diğer politikalarıyla olan ilişkisinin belirlenmesi ve çevrenin korunması amacıyla geliştirilmiştir. Metotta doğal alanların coğrafi dağılımı ve durumu, canlı ve bitki topluluklarının coğrafi dağılımı ve bolluk düzeyi, su kaynaklarının kalitesi ve bolluk düzeyi, arazi örtüsünün yapısı ve toprağın durumu, çevreye boşaltılan artıkların düzeyinin saptanması ve doğal zararların listesi gibi konularda envanter oluşturmak amaçlanmıştır (CORINE 2000).

CORINE programı, 1985 yilından 1990 yılına kadar Avrupa Komisyonu tarafindan yürütülmüş, terminolojisi ve metodolojisi geliştirilmiş ve Avrupa Birliği düzeyinde kabul edilmiştir. 1991 y1lı itibariyle 13 ülkede CORINE veritabanları oluşturulmuştur. Daha önceleri arazi örtüsü ile ilgili bilgiler sadece kentsel ve tarımsal gelişmeler ve ana altyapı projeleri gibi çalışmaların yürütüldüğü küçük alanlar için toplanırken, CORINE arazi örtüsü programı ile Avrupa Birliği Ülkeleri ve Birlik ölçeğinde çevre bilgilerinin toplanması, geliştirilmesi ve politikaların oluşturulması boyutuna ulaşmıştır (Aydınoğlu \& Yomralıŏlu 2008).

CORINE arazi kullanımı sinıflandırma yönteminin Türkiye'de uygulanabilirliğine yönelik çalışmalarda, Doğu Akdeniz kıyısında Mersin ve çevresinde Landsat-5 TM uydu verileri kullanılarak kontrolsüz (unsupervised) sınıflama yapılmış (Vural et al 1997), Isparta ili merkez ilçe arazilerinde Landsat-7 ETM uydu verisi ile hazırlanan CORINE haritasının \% 81.5 doğruluk sağladığı belirtilmiş (Başayiğit 2004), Çanakkale ilinde (Güre et al 2009) arazi kullanımına yönelik sonuçlar üretilmiştir. Ayrıca ülkenin tamamını kapsayan CORINE projesine 1998 yılında başlanmış, 2000 yılı Landsat uydu görüntüleri kullanılarak ilk haritalar üretilmiş çalışma 2008 yılı ortalarında tamamlanmıştır. 2006 yılı SPOT ve IRS uydu görüntüleri kullanılarak arazi örtüsü değişimlerinin haritalanmasını sağlamak 
amacıyla ikinci aşama çalışmalarına başlanmış, CORINE 2006 değişiklik tespiti projesi kapsamında 2000-2006 yılları arasında oluşan 5 ha'dan büyük tüm değişiklikler tespit edilerek ülkemiz ölçeğinde en güncel arazi kullanım haritaları oluşturma çalışmaları tamamlanmıştır. CORINE Projesi kapsamında, ölçek 1/100000, haritalanacak en küçük alan 25 ha, minimum koridor genişliği $100 \mathrm{~m}$, çalışılan hassasiyet ise 1/25000 olarak belirlenmiştir (Çivi et al 2009).

$\mathrm{Bu}$ çalışma, Eğirdir gölü kıyı kenar çizgisi esas alınarak oluşturulan 300-1000-2000-5000 m'lik koruma zonları için CORINE metoduna göre arazi kullanım haritasının hazırlanması amacıyla yapılmıştır.

\section{Materyal ve Yöntem}

\subsection{Materyal}

Çalışma, Eğirdir gölü çevresinde maksimum su kotundan itibaren belirlenen 5000 m'lik bir zonu kapsamaktadır (Şekil 1). Çalışmada Ağustos 2007 tarihinde 4 banttan alınan SPOT4 uydu verisi, Harita Genel Komutanlığınca hazırlanan toplam 20 adet 1/25000 ölçekli standart topoğrafik harita kullanılmıştır. Ayrıca haritaların sayısallaştırılmasında verilerin çakıştırılmasında ve sorgulanmasında ARCGIS 9.0, CBS yazılımı, uydu verilerinin işlenmesinde ERDAS 9.2 görüntü işleme yazılımı kullanılmıştır. Çalışma Süleyman Demirel Üniversitesi Ziraat Fakültesi Toprak Bilimi ve Bitki Besleme Bölümü Uzaktan Algılama ve CBS laboratuarında yürütülmüştür.

\subsection{Yöntem}

CORINE arazi kullanım türlerini belirlemek için SPOT-4 uydu verisinin 4, 2, 1 bant kombinasyonu kullanılmıştır. İlk önce uydu verisinin geometrik düzeltmesi yapılmış uzun mesafe koruma zonu mesafesine göre $(5 \mathrm{~km})$ uydu verisi kesilmiştir. Göl yüzeyi maskelenmiş ve uydu verisinden çıkartılmıştır.

Arazi çalışmaları için Eğirdir, Gelendost ve Yalvaç İlçelerinde $2 \times 2 \mathrm{~km}$ 'lik $\left(4 \mathrm{~km}^{2}\right) 3$ farklı test alanı belirlenmiş, uydu görüntüsüyle birlikte haritalar dizüstü bilgisayara yüklenerek GPS (Küresel Konumlama Cihazı) ile birlikte araziye çıkılmıştır.

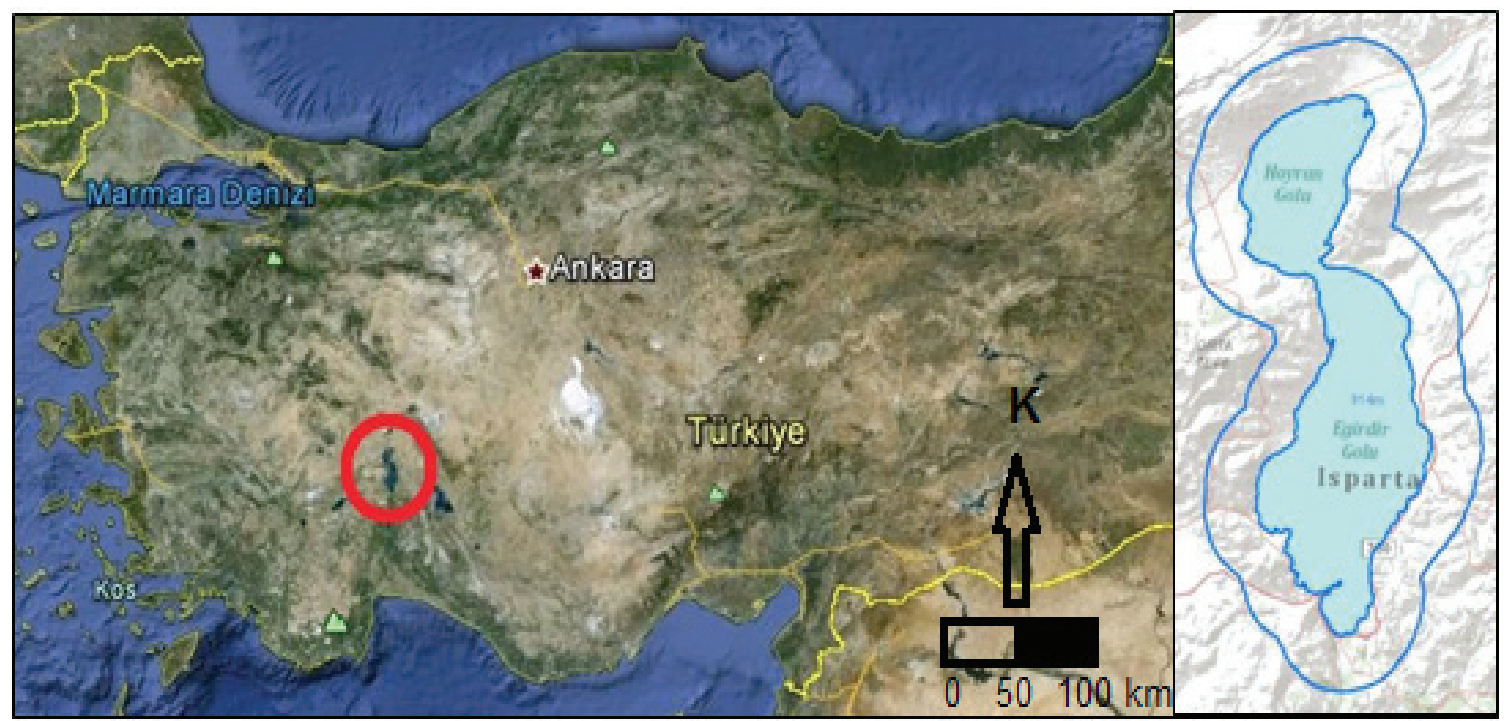

Şekil 1- Çalışma alanının konumu

Figure 1-Location of study area 


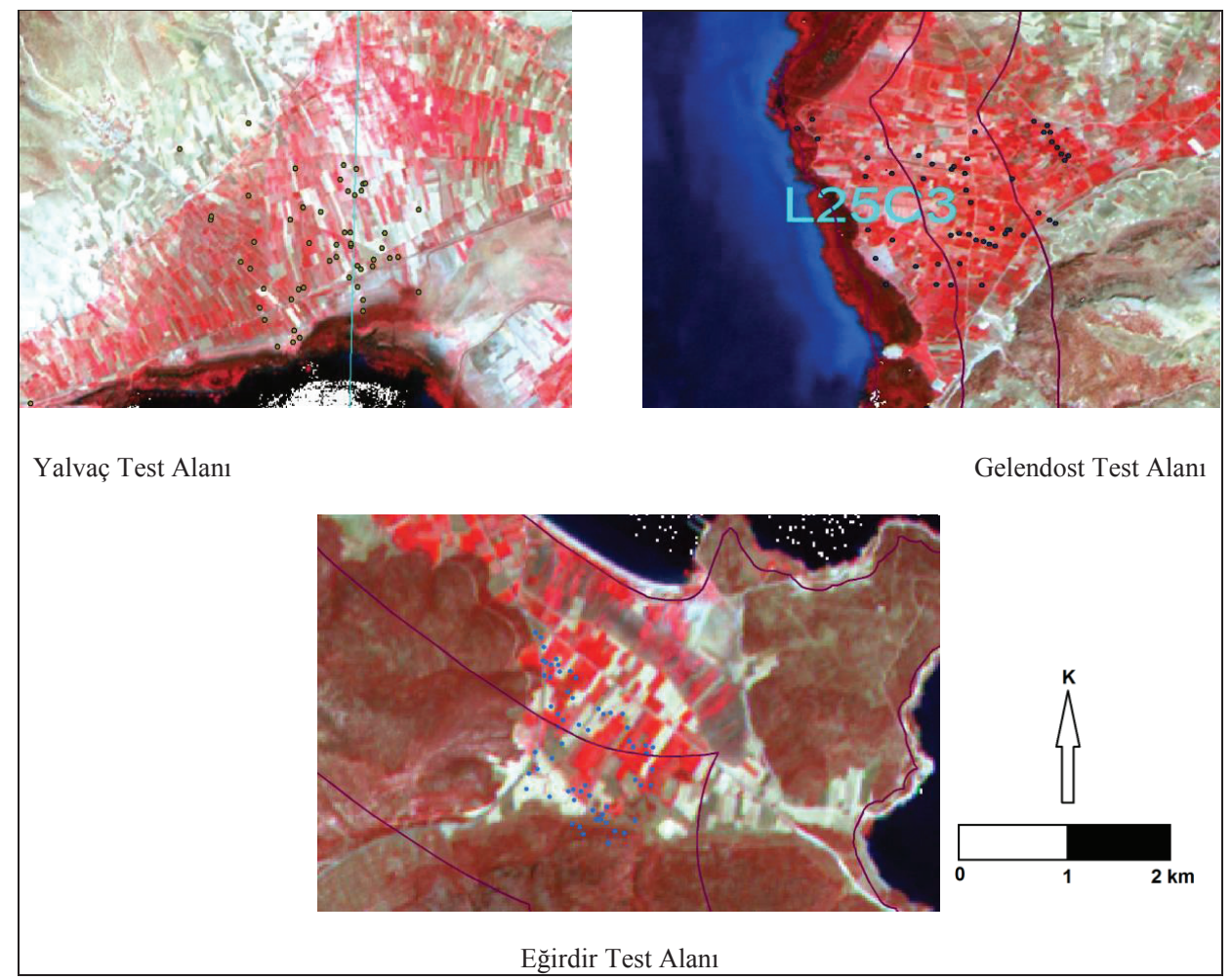

\section{Şekil 2- Test alanları ve kontrol noktaları}

Figure 2- Test area and control points

Her bir test alanında farklı arazi kullanım türleri olacak şekilde en az 50 kontrol noktasında örnekleme yapılmıştır. Noktaların koordinatları GPS ile belirlenmiş, fotoğrafları çekilmiş ve noktalara ilişkin ürün bilgileri not edilmiştir. Böylece uydu görüntüsü üzerinde yapılan kontrollü (supervised) sinıflamaya esas olacak şekilde ve CORINE metodunda belirtilen sınıfların belirlenmesinde altlık oluşturulmuştur. Şekil 2'de üç farklı test alanı ve kontrol noktaları yer almaktadir.

Örnekleme noktaları kullanılarak kontrollü sınıflama yapılmış uydu verisi üzerinde foto yorumlama ile ayırt edilen her türlü detay bir sınıf kabul edilmiş böylece toplamda 36 sınıf tanımlanmıştır. Tanımlanan sınıflarda yaklaşık 5 da'dan daha küçük (7x7 piksel) gruplar elenmiştir (eleminate 7x7) (ERDAS 1999). Arazi kontrolleri sonucu aynı arazi kullanım türlerine karşlık gelen sınıflar birleştirilmiştir.

Veri tabanı düzenlendikten sonra koruma mesafelerine göre "Su Kirliliği Kontrol Yönetmeliğì"nde belirtilmiş olan mutlak (0-300 $\mathrm{m})$, kisa $(300-1000 \mathrm{~m})$, orta $(1000-2000 \mathrm{~m})$ ve uzun (2000-5000 m) olmak üzere dört koruma zonu düzenlenmiş, CORINE yöntemine göre koruma zonlarındaki arazi kullanım durumu ortaya çıkarılmıştır (RG 2004).

\section{Bulgular ve Tartışma}

Standart renk kodları (CORINE 2000) kullanılarak üretilen tematik haritalar Şekil 3 ve 4'de verilmiştir. Alanda koruma zonlarına göre hesap edilen 
arazi kullanım türleri dağılımı Çizelge 1'de yer almaktadır. Çalışma alanında CORINE sınıflaması 1. seviye sınıflarından tamamı (yapay bölgeler, tarım alanları, orman ve yarı doğal alanlar, sulak alanlar ve su kütleleri) çalışma alanı içinde yer almıştır.

Kabul edilmiş CORINE sınıflarından yapay bölgeler grubunda; şehir yapısı, endüstriyel, ticari ve taşıma birimleri, maden alanları kullanılmıştır. Tarım alanları grubunda; tarla tarımı alanları, sürekli ürünler, meralar, heterojen tarım alanları kullanılmıştır. Orman ve yarı doğal alanlar grubunda; ormanlar, fundalık veya otsu bitkilerin karışım alanları, az veya hiç bitki içermeyen çıplak alanlar kullanılmış, su ile kaplı iç alanlar grubunda ise içsel su alanları kullanılmıştır.

Yapay bölgeler grubu içerisinde yer alan kullanım türlerinden liman, havalimanı boşaltım sahaları inşaat sahaları, yeşil şehir alanları ve spor ve eğlence alanları çalışma alanı içerisinde olmadığından CORINE arazi kullanım haritasında yer almamıştır. Tarım alanları grubu içerisinde yer alan kullanım türlerinden pirinç tarlaları ve zeytin bahçeleri bölgede yapılan tarım uygulamalarından olmadığ 1 için haritada yer almamıştır. Arazi çalışmalarında Senirkent ilçesinde üzüm bağlarının bulunduğu gözlemlenmiş ancak parseller alan olarak yeterli büyüklükte olmadığı için haritalamada kayıp bir sınıf olduğundan haritalanmamıştır. Sürekli ürünler ile birlikte bulunan senelik ürünler, karışık tarım alanları, ormanla karışık tarım alanları çalışma bölgesi içerisinde tanımlanmamıştır.

Orman ve yarı doğal grubu içerisinde yer alan kullanım türlerinden karışık ormanlar, çalışma ölçeği itibariyle sklerofil bitki örtüsü, iğne yapraklı ormanlar ve geniş yapraklı ormanlar olarak ayrıca ayırt edilebildiği için sınıflamaya dâhil edilmemiştir. Fundalık araziler, yanmış araziler ve buzul ve kalıcı kar örtüleri çalışma alanında bulunmamaktadır. Su ile kaplı iç alanlar grubu içerisinde yer alan kullanım türlerinden turbalıklar, tuz bataklığ 1 , tuzlalar ve gel git olayı ile oluşan düzlükler çalışma alanında yer almamaktadır.

Son olarak sulak alanlar ve su kütleleri türlerinden suyolları ve kıyı lagünleri, nehir ağızları ile deniz ve okyanus sınıfları çalışma bölgesinde yer almadığı için arazi kullanım haritasına dâhil edilmemiştir. Çalışma alanında 3. seviye sınıflamada en fazla orman arazilerinin bulunduğu, en az ise şehir, ticari ve maden alanları gibi bitki örtüsünün olmadığ1 alanlardan oluştuğu görülmektedir. Alanın yaklaşık \% 35 'ini oluşturan orman alanlarının büyük kısmını iğne yapraklı ormanlar ile maki türü sklerofil bitki örtüsü oluşturmaktadır. Çalışma alanının \% 7.29'unu meyve bahçeleri oluşturmaktadır. Bölgedeki kuru tarım alanlarında arpa ve buğday tarımı yapılmakta olup bu alanın \% 13.92'lik önemli bir kısmına karşılık gelmektedir. Kuru tarım alanları CORINE sinıflamasında sulanmayan ancak ekilebilir alanlar olarak verilmiştir.

Mera arazileri çalışma bölgesinin \% 3.10'luk kısmını oluşturmuştur. Nitekim Tarım ve Köyişleri Bakanlığının MERBİS Projesi incelendiğinde Isparta ili mera arazi varlığı, il yüzölçümünün yaklaşık olarak \% 2'sine karşılık geldiği görülmüştür (Gençer \& Başayiğit 2010). Bataklık ve sahil, kumsal, kumluk olarak nitelendirilebilecek alanlar göle sıfır konumda olup, bu alanların bir kısmı maksimum su kodunun içinde kalmaktadır. Yapay alanlar çalışma alanının yaklaşık olarak $\%$ 1.2'sini oluşturmaktadır. Bu alanlar SPOT uydu verisinin sınıflandırmasında ayırt edilemediği için 1/25000 ölçekli topoğrafik haritalar ve Google Earth kullanılarak sınıflandırılmış görüntü üzerine çakıştırılmıştır. Doğal bitki örtüsü ile birlikte bulunan tarım alanları çalışma alanının \% 7.20'lik bir kısmını oluşturmaktadır. Bu kullanım türü sklerofil bitki örtüsü, diğer iğne ve geniş yapraklı ağaçlar ve doğal çayır karışımı içerisinde tarım yapılan alanlar için kullanılan bir sınıfa karşılık gelmektedir. Ayrıca orman vasfını yitirmiş tarım arazisi olarak kullanılan alanlar da bu kategoride yer almaktadır. 3. düzey sınıflamada yer alan seyrek bitki alanları çalışma alanının yaklaşık olarak \% 5'ine karşılık gelmektedir. Bu alanlar bitki örtüsünün az olduğu ya da hiç olmadığı alanlardır. Doğal çayırlık olarak nitelendirilen alanlar ise çalışma alanının \% 13'lük önemli bir kısmını kapsamakta olup otsu bitkilerle kaplı alanlardir. 


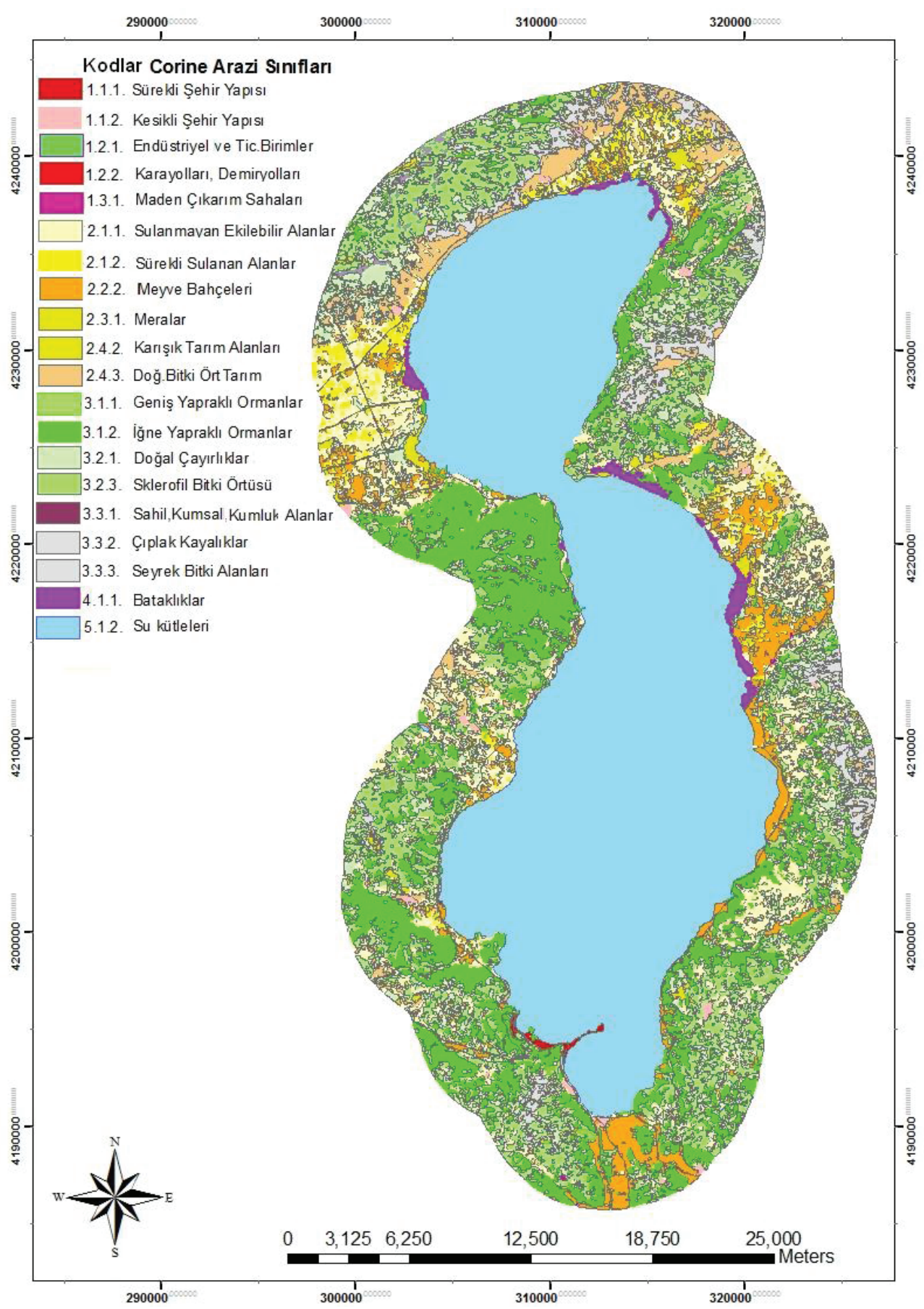

Şekil 3- CORINE arazi kullanım haritası

Figure 3-CORINE land use map 


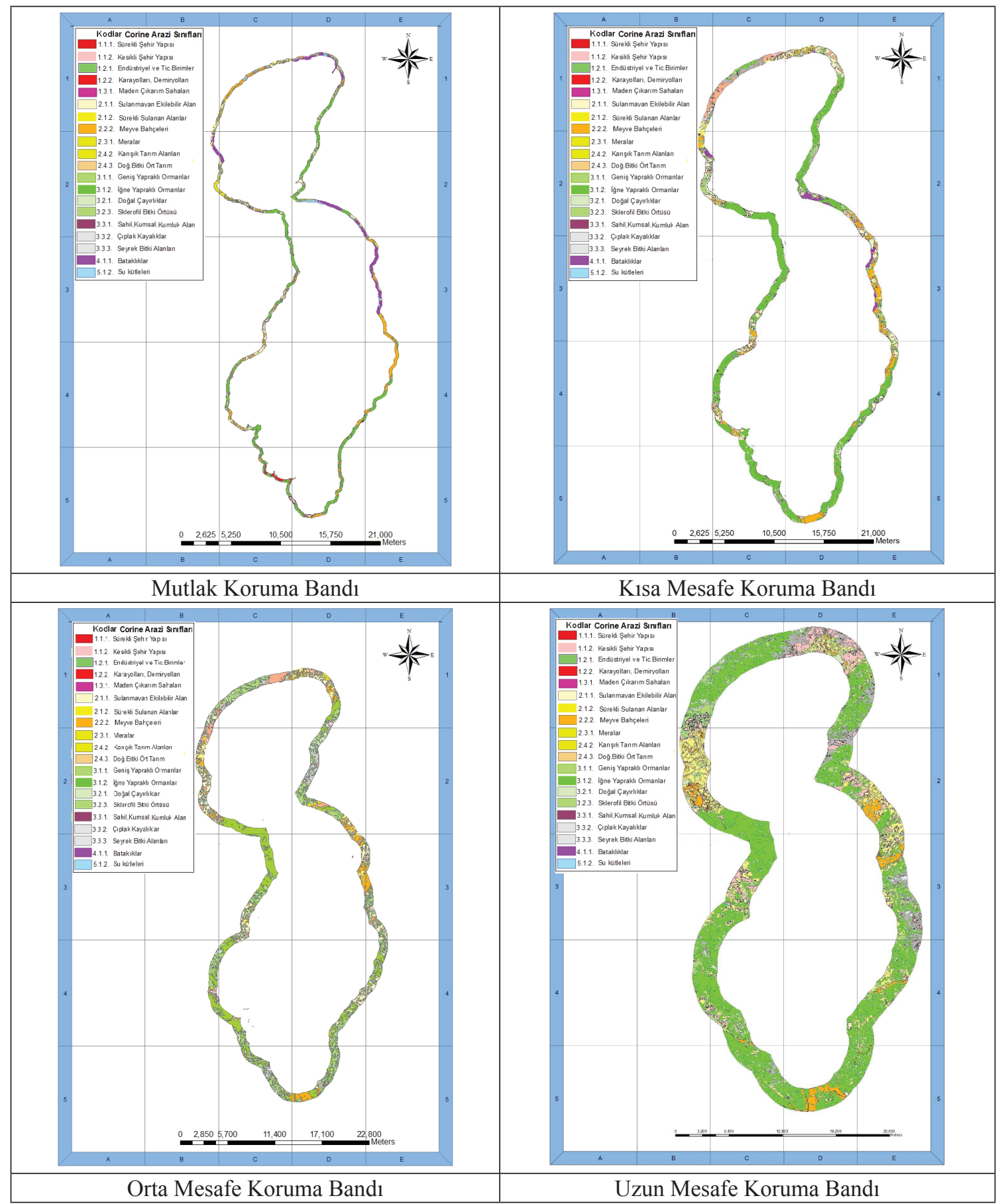

Şekil 4- Mutlak koruma zonları CORINE arazi kullanım haritaları

Figure 4-CORINE land use map of absolute protection zone 
Çizelge 1- Koruma zonlarına göre CORINE arazi kullanım dağılımları

Table 1- The distribution of CORINE land use types for protection zones

\begin{tabular}{|c|c|c|c|c|c|c|c|c|c|c|c|}
\hline \multirow[b]{2}{*}{ Kodlar } & \multirow[b]{2}{*}{ CORINE arazi sinıflarl } & \multicolumn{2}{|c|}{ Çalışma alanı } & \multicolumn{2}{|c|}{$\begin{array}{c}\text { Mutlak koruma } \\
\text { zonu (MKZ) }\end{array}$} & \multicolumn{2}{|c|}{$\begin{array}{c}\text { Klsa mesafe } \\
\text { koruma zonu } \\
\text { (KMZ) }\end{array}$} & \multicolumn{2}{|c|}{$\begin{array}{c}\text { Orta mesafe } \\
\text { koruma zonu } \\
\text { (OMZ) }\end{array}$} & \multicolumn{2}{|c|}{$\begin{array}{c}\text { Uzun mesafe } \\
\text { koruma zonu } \\
\text { (UMZ) }\end{array}$} \\
\hline & & (da) & $(\%)$ & (da) & $(\%)$ & (da) & $(\%)$ & (da) & $(\%)$ & (da) & $(\%)$ \\
\hline & Toplam & 708799.80 & 100 & 41760.11 & 100 & 94940.07 & 100 & 136155.9 & 100 & 422588.2 & 100 \\
\hline 1.1.1. & Sürekli şehir yapısı & 621.75 & 0.09 & 619.07 & 1.48 & 2.68 & 0.00 & - & - & - & - \\
\hline 1.1.2. & Kesikli şehir yapısı & 3211.36 & 0.46 & 476.74 & 1.14 & 424.66 & 0.45 & 629.56 & 0.46 & 1680.40 & 0.40 \\
\hline 1.2 .1 & Endüstriyel ve ticari birimler & 148.90 & 0.02 & - & - & - & - & - & - & 148.90 & 0.04 \\
\hline 1.2 .2 & $\begin{array}{l}\text { Karayolları, demiryolları ve ilgili } \\
\text { alanlar }\end{array}$ & 3835.59 & 0.55 & 884.08 & 2.12 & 703.34 & 0.74 & 693.09 & 0.51 & 1555.08 & 0.37 \\
\hline 1.3.1. & Maden çıkarım sahaları & 70.64 & 0.01 & - & - & - & - & - & - & 70.64 & 0.02 \\
\hline 2.1 .1 & Sulanmayan ekilebilir alanlar & 96806.92 & 13.92 & 5081.63 & 12.17 & 13361.36 & 14.07 & 21321.57 & 15.66 & 57042.36 & 13.50 \\
\hline 2.1 .2 & Sürekli sulanan alanlar & 18320.85 & 2.63 & 1247.63 & 2.99 & 3042.28 & 3.20 & 4449.84 & 3.27 & 9581.10 & 2.27 \\
\hline 2.2 .2 & Meyve bahçeleri & 50686.19 & 7.29 & 6451.34 & 15.45 & 11159.22 & 11.75 & 10991.72 & 8.07 & 22083.91 & 5.23 \\
\hline 2.3 .1 & Meralar & 21571.78 & 3.10 & 1769.91 & 4.24 & 4626.32 & 4.87 & 4037.65 & 2.97 & 11137.9 & 2.64 \\
\hline 2.4 .2 & Karışık tarım alanları & 110.10 & 0.02 & - & - & 11.33 & 0.01 & 98.77 & 0.07 & - & - \\
\hline 2.4 .3 & $\begin{array}{l}\text { Doğal bitki örtüsü ile birlikte } \\
\text { bulunan tarım alanları }\end{array}$ & 50085.25 & 7.20 & 2113.55 & 5.06 & 6261.16 & 6.59 & 10208.04 & 7.50 & 31502.50 & 7.45 \\
\hline 3.1 .1 & Geniş yapraklı ormanlar & 372.73 & 0.05 & - & - & 231.93 & 0.24 & 94.78 & 0.07 & 46.02 & 0.01 \\
\hline 3.1 .2 & İğne yapraklı ormanlar & 141961.30 & 20.41 & 9220.41 & 22.08 & 27863.02 & 29.35 & 30334.83 & 22.28 & 74543.04 & 17.64 \\
\hline 3.2 .1 & Doğal çayırlıklar & 93408.10 & 13.43 & 3320.85 & 7.95 & 9275.90 & 9.77 & 18078.85 & 13.28 & 62732.50 & 14.84 \\
\hline 3.2 .3 & Sklerofil bitki örtüsü & 171242.10 & 24.62 & 4241.02 & 10.16 & 13342.50 & 14.05 & 31572.54 & 23.19 & 122086.04 & 28.89 \\
\hline 3.3.1. & Sahiller, kumsallar, kumluklar & 15.99 & 0.00 & 15.95 & 0.04 & 0.04 & 0.01 & - & - & - & - \\
\hline 3.3.2. & Çıplak kayalıklar & 1968.15 & 0.28 & 79.26 & 0.19 & 143.60 & 0.15 & 253.35 & 0.19 & 1491.94 & 0.35 \\
\hline 3.3.3. & Seyrek bitki alanları & 32874.61 & 4.73 & 543.47 & 1.30 & 2158.94 & 2.27 & 3391.32 & 2.49 & 26780.88 & 6.34 \\
\hline 4.1.1. & Bataklıklar & 7128.58 & 1.03 & 4796.79 & 11.49 & 2331.79 & 2.46 & - & - & - & - \\
\hline 5.1 .2 & Su kütleleri & 1003.41 & 0.14 & 898.41 & 2.15 & - & - & - & - & 105.00 & 0.02 \\
\hline
\end{tabular}

\subsection{Koruma zonlarl CORINE arazi kullanim haritalart}

Mutlak koruma zonu, kisa mesafe koruma zonu, orta mesafe koruma zonu ve yakın mesafe koruma zonu için hazırlanan CORINE arazi kullanım haritaları Şekil 4'de verilmiştir. Çalışma alanında arazi kullanım türlerinin koruma zonlarına göre dağılım oranları Şekil 5'de verilmiştir. Buna göre her bir koruma zonuna ait arazi kullanım türleri aşağıda açıklanmıştır.

\subsection{Mutlak koruma zonu CORINE arazi kullanım türleri dă̆ılımı}

İçme ve kullanma suyu rezervuarının maksimum su seviyesinden itibaren $300 \mathrm{~m}$ genişliğindeki şerit mutlak koruma zonu olarak tanımlanmaktadır. Mutlak koruma zonu içersinde en fazla tanımlanan arazi kullanım türü \% 22.08 ile iğne yapraklı ormanlar en az tanımlanan arazi kullanım türü ise $\% 0.03$ ile sahiller, kumsallar ve kumluklar olmuştur. Sklerofil bitki örtüsü olarak tanımlanan makilik arazilerde $\%$ 10.16'lık bir oranda olduğu belirlenmiştir. Buna göre kısa mesafe koruma zonu içerisinde yer alan arazilerin üçte birlik bölümünü ormanlar ve maki arazileri oluşturmaktadır. $\mathrm{Bu}$ zonda bölge tarımı açısından önemli yer tutan meyve bahçeleri ise \% $15.45^{\prime}$ lik bir orana sahip olup 645 hektarlık bir alanı kapsamaktadır. İkinci düzeyde tarım alanları olarak tanımlanan arazilerin toplamı koruma zonunun \% 40'ına karşılık geldiği belirlenmiştir. Göl havzasında bataklık olarak nitelendirilen arazilerin büyük çoğunluğu mutlak koruma zonunda kalmaktadır. Bataklıkların mutlak koruma zonu içerisindeki oranı 


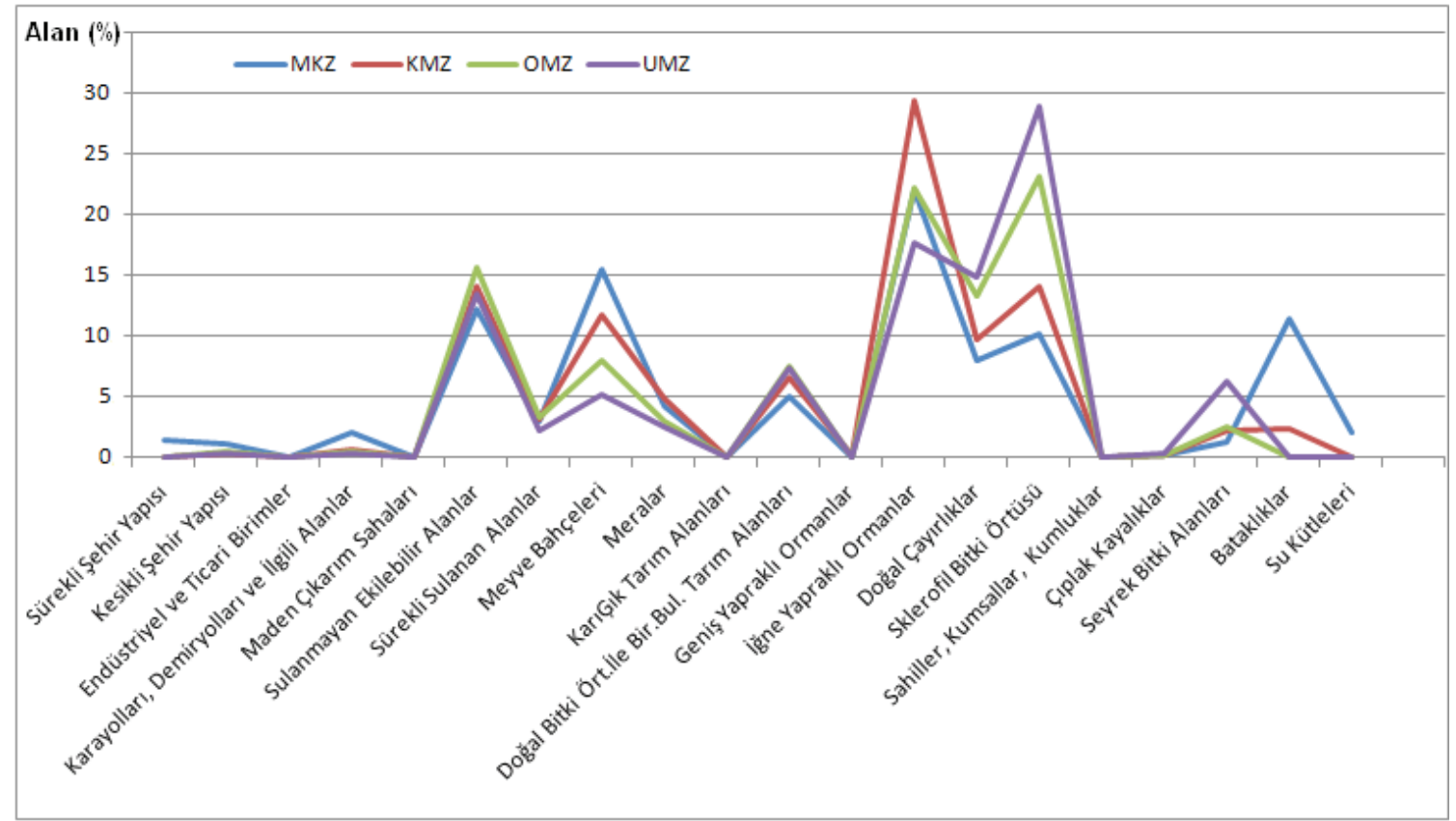

MKZ, mutlak koruma zonu; KMZ, kisa mesafe koruma zonu; OMZ, orta mesafe koruma zonu; UMZ, uzun mesafe koruma zonu

\section{Şekil 5- CORINE arazi kullanım türlerinin koruma zonlarına göre dağılımı}

Figure 5- The distribution of CORINE land use types according to protection zones

ise $\% 11$ dir. $\mathrm{Bu}$ alanlar doğal ya da su kullanımı nedeniyle gölün çekilmesi sonucu oluşan zayıf geçirgen alanlara karşılık gelmektedir. Mera olarak nitelendirilen araziler korumada bu zonun \% 4'lük kısmını oluşturmaktadır. Meralar göl kıyısında gölden beslenen zaman zaman taban suyunun yükseldiği, yağışsız mevsimlerde ve kurak dönemlerde gölün çekilmesiyle oluşan taban meraları şeklindedir. Her an yeniden su altında kalma riski bulunan bu alanlar taban suyu yüksek arazilerdir. Sahiller, kumsallar, kumluklar olarak nitelendirilen araziler Eğirdir ilçesinde yer almakta olup, bu sinıfta yer alan araziler bölge halkı tarafından fiili olarak kullanılmaktadır.

\subsection{Klsa mesafe koruma zonu CORINE arazi kullanım türleri dağılımı}

Kısa mesafeli koruma zonu, içme ve kullanma suyu rezervuarlarının mutlak koruma zonu sinırından itibaren $700 \mathrm{~m}$ genişliğindeki şerittir. Bu koruma zonunda yer alan araziler içerisinde en yüksek orana sahip alanlar \% 29.35 ile iğne yapraklı ormanlardır. Sahiller, kumsallar ve kumluklar ise en düşük orana sahiptir. Bu arazi tipleri göl kıyısından uzaklaşılması nedeniyle $300 \mathrm{~m}$ sonrasında hemen hemen hiç kalmamaktadır. Orman arazileri açısından koruma zonu incelendiğinde çalışma bölgesinin tamamında olduğu gibi kısa mesafe koruma zonunda da iğne yapraklı ormanların ağırlıkta olduğu, geniş yapraklı ormanların ise az miktarda olduğu tespit edilmiştir. Sklerofil bitki örtüsü olarak tanımlanan maki arazileri ise bu zonda \% 14.08'lik bir orana sahiptir. Meyve bahçeleri ise kısa mesafe zonunun \% 11.75 'lik bir bölümünü oluşturduğu, mutlak koruma zonu ile karşılaştırıldığında kısa mesafe zonundaki oranında azalma olduğu, fakat genel toplamda bakıldığında \% 7'lik ortalamanın üzerinde olduğu tespit edilmiştir. Sulanmayan ekilebilir alanların ise bu zonun \% 14.07'lik kısmını oluşturduğu, koruma zonunda kuru tarımın da yaygın olarak yapıldığı ortaya çıkmaktadır. Mutlak koruma zonu ile karşılaştırıldığında kuru 
tarım yapılan arazilerin oransal dağılımında artış görülmektedir. Mera arazilerinin oransal değeri \% 4.07 olup bu oran mutlak koruma zonuna göre sabit kaldığı görülmüştür. Bu koruma zonunda orman sayılan arazilerle birlikte maki niteliği taşıyan alanların tarım yapılan alanlardan daha fazla olması ve mutlak koruma zonu ile karşılaştırıldığında işlemeli tarım yapılan arazilerin azalmasının nedenleri olarak; arazi yapısındaki engebeliliğin artışı, toprak derinliğinin azalışı, bünyenin kabalaşması, göle olan uzaklığın artması ve sulamanın zorlaşması gösterilebilir.

\subsection{Orta mesafe koruma zonu CORINE arazi kullanım türleri dağılımı}

Orta mesafeli koruma zonu, içme ve kullanma suyu rezervuarlarının kısa mesafeli koruma alanı sınırından itibaren $1 \mathrm{~km}$ genişliğindeki şerittir. $\mathrm{Bu}$ koruma zonunda kalan araziler içerisinde en yüksek orana sahip alanları \% 23.19 ile sklerofil bitki örtüsü olarak tanımlanan makilikler, en düşük orana sahip alanları ise \% 0.07 ile geniş yapraklı ormanlar oluşturmaktadır. Orta mesafeli koruma zonu ile kisa mesafe koruma zonu karşılaştırıldığında meyve bahçeleri dağılımda $\%$ 8'lik bir azalma olduğu görülmektedir. Orta mesafeli koruma zonunda sulanmayan ekilebilir alanların oranı ise \% 15.66 olarak belirlenmiştir. $\mathrm{Bu}$ bölgede kuru tarım yapılan alanlarda bir artış bulunmaktadır. Sürekli sulanan alanlarda toplam tarım yapılan alanların oranında bir miktar azalma olduğu tespit edilmiştir. Doğal bitki örtüsü ile birlikte bulunan tarım alanları, bu zonu oluşturan toplam alanın \% 7.50'sine karşılık gelmektedir. $\mathrm{Bu}$ oran k1sa mesafe koruma zonuna göre bir miktar fazladır. $\mathrm{Bu}$ zonda yaklaşık \% 45'lik gibi önemli bir kısmının orman arazilerine denk geldiği görülmektedir. Mera arazileri ise toplam alanının \% 3'lük kısmını oluşturduğu, kısa ve orta mesafe koruma zonlarına göre bir miktar azalma olduğu görülmektedir. $\mathrm{Bu}$ durum üzerinde en etkili faktör arazinin sahip olduğu topoğrafik koşullardır.

\subsection{Uzun mesafe koruma zonu CORINE arazi kullanım türleri dağılımı}

Uzun mesafeli koruma zonu içme ve kullanma suyu rezervuarlarının orta mesafeli koruma zonu sınırından itibaren 3 kilometre genişliğindeki şerittir. $\mathrm{Bu}$ koruma zonunda kalan araziler içerisinde en yüksek orana sahip olan arazi kullanım türü \% 28.89 ile sklerofil bitki örtüsüdür. En düşük orana sahip olan ise geniş yapraklı orman alanlarıdır. Sklerofil bitki örtüsü olarak tanımlanan maki arazileri ile doğal çayırlık olarak nitelendirilen arazilerin oransal dağılımındaki artışın temel nedeni topoğrafik yapı ve toprak özellikleridir. $\mathrm{Bu}$ bölgede tarım alanlarının oranı \% 20 civarındadır. Uzun mesafe koruma zonunda meyve bahçesi olarak nitelendirilen araziler toplam alanın \% 5.23'üne karşılık gelmektedir. $\mathrm{Bu}$ miktar diğer koruma zonlarına göre azalma göstermektedir. Sulanmayan ekilebilir olarak nitelendirilen alanların oransal dağılımı ise $\% 13.50$ 'dir. Mera arazileri toplam alanın yaklaşık olarak \% 2.64'üne karşılık gelmektedir. $\mathrm{Bu}$ dağılım genel ortalamanın biraz altındadır. Seyrek bitki alanı olarak nitelendirilen araziler toplam alanın \% 6.34'üne karşılık gelmektedir. Bu oranın genel tüm çalışma alanı ile kıyaslandığında daha fazla olduğu görülmektedir. Bunun sebebi ise gölden uzaklaştıkça topografyanın daha engebeli hale gelmesi sonucu tarımsal amaçlı kullanılan arazilerin yerini meraların almasıdır. Bölgede yapılan benzer çalışmada Landsat 7 (ETM+) kullanılarak Isparta-Merkez ilçesinin CORINE arazi kullanımı sınıflandırması yapılmış, 3 . düzeyde 26 farklı arazi kullanım türü belirlenmiştir. Alanda en fazla orman ve yarı doğal alanlar en az ise su yüzeyleri belirlenmiştir. Oluşturulan sonuç haritasının doğruluğu; \% 81.5 olarak hesaplanmıştır (Başayiğit 2004).

\subsection{CORINE haritası ile karşılaştırılması}

Yapılan çalışma Çevre ve Orman Bakanlığının CORINE 2006 projesi ile karşılaştırıldığında farklılıklar görülmektedir (Çizelge 2). Farklılığın temel sebebi CORINE 2006 projesinin haritalama ölçeği $1 / 100000$, en düşük haritalama alanı ise 25 ha olarak seçilmiş olmasıdır. Bu çalışmada ise haritalama ölçeği $1 / 25000$, en küçük haritalama alanı ise çok küçük poligonların elenmesinin ardından yaklaşık 1 dekardır. Ayrıca bu çalışmada endüstriyel ve ticari birimler, maden çıkarım 
sahaları, karayolları, demiryolları ve ilgili alanlar, sahiller, kumsallar, kumluklar ve su kütleleri sınıfları 1/25000 ölçekli topografik harita ve uydu verisi yardımıyla sayısallaştırılmıș olup mevcut proje üzerine çakıştırılmıştır. Oysa bu alanlar 25 hektardan daha küçük bir alan kapsadığ 1 için CORINE 2006 projesinde yer almamıştır. Benzer olarak iki çalışmada karışık tarım olarak nitelendirilen alanlar arasındaki farkın da kontrollü sınıflama sonucunda ayırt edilebilmesinden kaynaklandığı belirlenmiştir. Tarım alanlarının toplamı olarak nitelendirilen sulanmayan ekilebilir alanlar, sürekli sulanan alanlar ve meyve bahçelerinin toplamı iki çalışmada da benzer değerler verirken bu kullanım türlerinin her birinin ayrı ayrı değerlendirilmesinde farklılıklar olduğu görülmektedir (Şekil 6).

\section{Sonuçlar}

$\mathrm{Bu}$ çalışmada öncelikli olarak kontrolsüz sınıflandırma metodu arazi çalışmalarından önce denenmiş fakat CORINE arazi kullanım haritası için kontrollü sınıflandırmanın daha uygun olduğu kanaatine varılmıştır. CORINE arazi kullanım sınıflamasında şehir yapıları, karayolları, ticari birimler ve sahil gibi sınıfların sınıflandırma işlemi ile ayırt edilemediği ve haritalanmanın mümkün olmadığ 1 durumlarda topografik harita ve google earth gibi verilerin yardımıla "manual" olarak harita üzerine çakıştırılması zorunlu olmuştur. Sinıflandırma metodu veya sayısallaştırma metotlarından sadece bir tanesinin uygulanmasiyla CORINE arazi örtüsünde farklı kategorik düzeylerde yer alan birçok sınıfın belirlenemeyeceği sonucuna

\section{Çizelge 2- Çalışma alanının CORİNE 2006 haritası ile karşılaştırılması}

Table 2- The comparison of study area with CORINE 2006 map

\begin{tabular}{lcrrr}
\hline CORINE arazi sinıflarl & Kodlar & $\begin{array}{r}\text { CORINE2006 } \\
\text { projesi (\%) }\end{array}$ & $\begin{array}{r}\text { Calışma } \\
\text { (\%) }\end{array}$ & $\begin{array}{c}\text { Fark } \\
\text { (\%) }\end{array}$ \\
\hline Sürekli şehir yapısı & 1.1 .1$. & --- & 0.17 & 0.17 \\
Kesikli şehir yapısı & 1.1 .2$. & 1.45 & 0.46 & 0.99 \\
Endüstriyel ve ticari birimler & 1.2 .1$. & --- & 0.03 & 0.03 \\
Karayolları, demiryolları ve ilgili alanlar & 1.2 .2$. & --- & 0.6 & 0.6 \\
Maden çıkarım sahaları & 1.3 .1$. & --- & 0.01 & 0.01 \\
Sulanmayan ekilebilir alanlar & 2.1 .1$. & 7.37 & 13.88 & 6.51 \\
Sürekli sulanan alanlar & 2.1 .2$. & 7.43 & 2.61 & 4.82 \\
Üzüm bağları & 2.2 .1$. & 0.22 & --- & 0.22 \\
Meyve bahçeleri & 2.2 .2$. & 5.54 & 7.38 & 1.84 \\
Meralar & 2.3 .1$. & 1.39 & 3.09 & 1.7 \\
Karışık tarım alanları & 2.4 .2$. & 9.97 & 0.01 & 9.96 \\
Doğal bitki örtüsü ile birlikte bulunan tarım alanları & 2.4 .3$. & 8.77 & 7.28 & 1.49 \\
Geniş yapraklı ormanlar & 3.1 .1$. & 1.3 & 0.05 & 1.25 \\
İğne yapraklı ormanlar & 3.1 .2$. & 2.73 & 20.32 & 17.59 \\
Karışı ormanlar & 3.1 .3$. & 0.86 & --- & 0.86 \\
Doğal çayırlıklar & 3.2 .1$. & 5.15 & 13.34 & 8.19 \\
Sklerofil bitki örtüsü & 3.2 .3$. & 17.9 & 24.34 & 6.34 \\
Bitki değişim alanları & 3.2 .4$. & 14.75 & --- & 14.75 \\
Sahiller, kumsallar, kumluklar & 3.3 .1$. & --- & 0.01 & 0.01 \\
Çıplak kayalıklar & 3.3 .2$. & 0.72 & 0.28 & 0.44 \\
Seyrek bitki alanları & 3.3 .3$. & 11.88 & 4.86 & 7.02 \\
Bataklıklar & 4.1 .1$. & 2.57 & 1.25 & 1.32 \\
Su kütleleri & 5.1 .2$. & --- & 0.015 & 0.015 \\
\hline
\end{tabular}




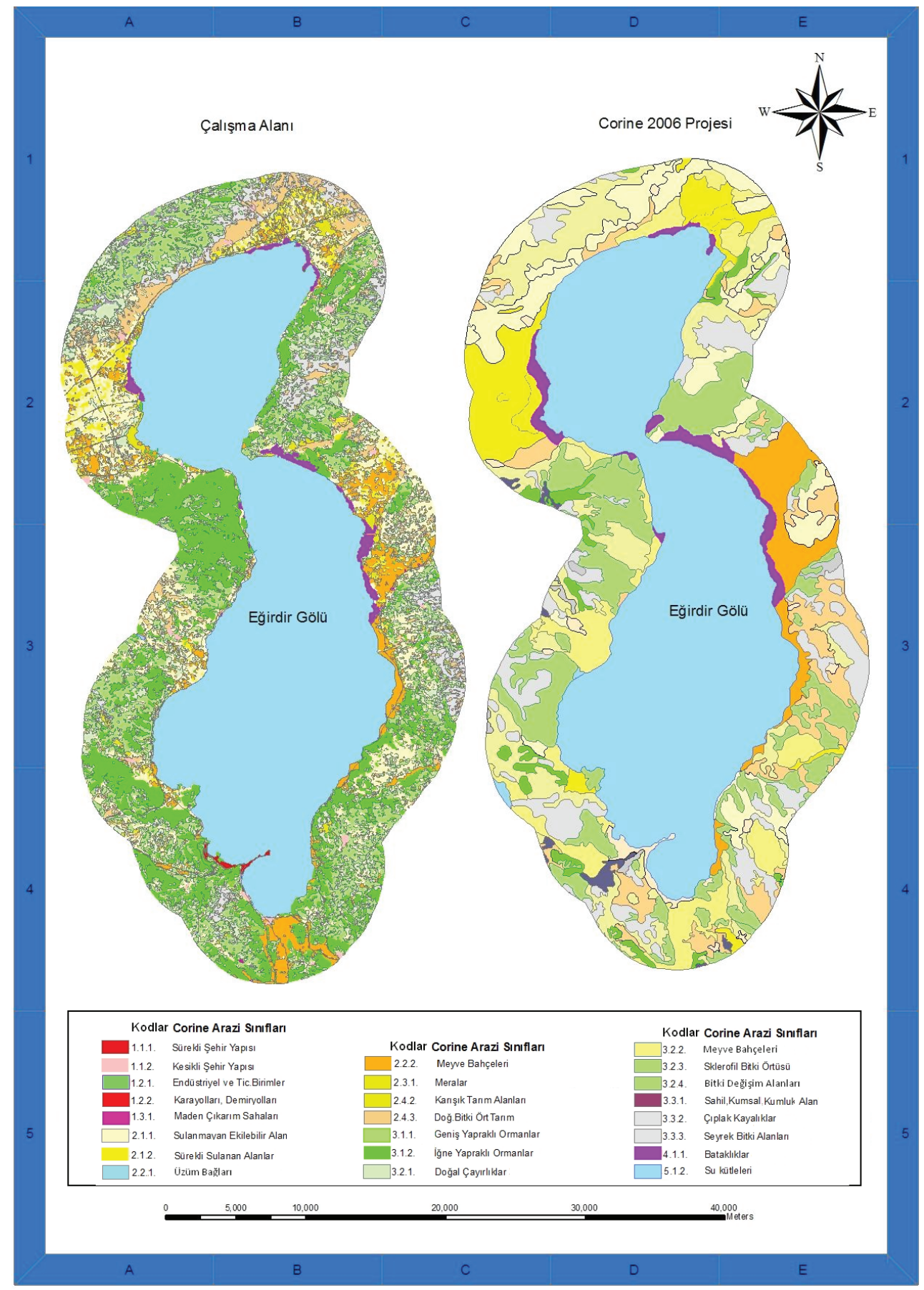

Şekil 6- Çalışmada üretilen CORINE haritası ve CORINE 2006 haritası

Figure 6- The produced CORINE map of this study and CORINE 2006 map 
varılmıştır. CORINE metodu ile oluşturulan haritalar ileride göl çevresinde yapılacak çalışmalara altlık olabilecek özellikte bulunmuştur. Ayrıca benzer çalışmalarda aynı metodun uygulanması arazilerdeki yıllara bağlı olarak gerçekleşecek değişimin belirlenebilmesini sağlayacaktır.

Çalışma alanında bulunan 621.75 da alana sahip olan sürekli şehir yapısının 619.07 da'1 mutlak koruma zonunda geriye kalan 2.68 da'1 ise kısa mesafe koruma zonunda yer almaktadır. Alanda bulunan 3211.36 da kesikli şehir yapısının 1680.40 uzun mesafe koruma zonunda yer alması Eğirdir İlçesinin göl kenarında köy ve kırsalların ise göl kıyısından daha uzakta yer almasından kaynaklanmaktadır. Endüstriyel ve ticari birimlerin tamaminın mutlak koruma zonunda yer almas1 iş ve sanayi bölgelerinin Eğirdir ilçe merkezinde olması, dolayısıyla ilçe merkezinin de göl kıyısında bulunmasıyla ilgilidir. Sürekli sulanan alanlar ve sulanmayan ekilebilir alanların oranları tüm koruma zonlarında birbirine yakındır. Sürekli sulanan alanlar ve meyve bahçelerinin oranları ise doğal olarak gölden uzaklaştıkça azalmaktadır. Meralar da benzer özellik göstermektedir.

Karışık tarım alanları düzgün dağılım göstermemektedir. $\mathrm{Bu}$ sinıf bir ara sinıf olmas1 nedeniyle her bölge için farklılık göstermektedir. Doğal bitki örtüsü ile birlikte bulunan tarım alanlarının gölden uzaklaştıkça arttığı belirlenmiştir. $\mathrm{Bu}$ durum göl çevresine müdahalenin daha fazla olduğu anlamına gelmektedir. Geniş yapraklı ormanların en fazla kısa mesafe koruma zonunda yer alması orta ve uzun mesafe koruma zonunda azalması ve mutlak koruma zonunda hiç olmaması bu bitkilerin yetişme ortamlarıyla alakalıdır. Orman ve yarı doğal alanlar grubunda bulunan iğne yapraklı ormanlar, doğal çayırlıklar, sklerofil bitki örtüsü ve seyrek bitki örtüsü olarak sınıflandırılan yerler en az mutlak koruma zonunda en fazla uzun mesafe sonunda bulunmuştur. Ayrıca bu sınıfların yayılım alanları gölden uzaklaştıkça artış göstermektedir. $\mathrm{Bu}$ durum bitkilerin yetişme ortamlarıyla alakalıdır. Çıplak kayalıklarda benzer özellik göstermesi alanın topografik karakteristiklerinden kaynaklanmaktadır. Bunun aksine sahil, kumsal, kumluk ve bataklikların uzun mesafe zonlarında azalması gölden uzaklaştıkça doğal olarak göl oluşumlarının bulunmaması ile ilgilidir.

Haritalama ölçeği ve haritalanan en küçük alanın büyüklüğü çalışmanın kalitesini doğrudan etkilediği görülmüştür. Türkiye'nin tamamı için yapılan CORINE haritalarının daha büyük ölçekte ve daha detaylı olarak güncellenmesi ile kullanılabilirliği yüksek temel haritalara dönüşebileceği sonucuna varılmıştır.

\section{Kaynaklar}

AB (2011). Çevre ve Orman Bakanlığı 2004. http://www. mevzuat.adalet.gov.tr/ html/21744.html. (Erişim tarihi: 20.05.2011)

Aydınoğlu A C \& Yomralığlu T (2008). Arazi Örtüsünü Temsil Eden Coğrafi Veritabanı Tasarımı, 2. Uzaktan Algılama ve Coğrafi Bilgi Sistemleri Sempozyumu, 13-15 Ekim, Kayseri

Başayiğit L (2004). CORINE Arazi kullanımı sınıflandırma sistemine göre arazi kullanım haritasının hazırlanmas1. Tarım Bilimleri Dergisi 10(4): 66-374

CORINE (2000). CORINE land cover technical project guide. European Environmental Agency s: 4-5

Çivi A, Akgündüz E, Kalaycı K, İnan Ç, Sarıca E \& Toru E (2011). Corine projesi. Tufuab 2011 6.Teknik Seтроzуити, 23-26 Şubat, Antalya, poster bildirisi

Çivi A, Akgündüz E, Kalaycı K, İnan Ç, Sarıca E \& Toru E (2009). CORINE (Coordination of Information on the Environment) projesi TMMOB Coğrafi Bilgi Sistemleri Kongresi, 02-06 Kasım, poster bildirisi, İzmir

ERDAS (1999). Erdas imagine field guide $4^{\text {th }}$ Ed., 2801. Buford Highway, N.E.Atlanta, Georgia,USA, s: 244

Gençer M \& Başayiğit L (2010). Isparta ili mera tahdit çalışmaları bitirilmiş parsellerin CBS ortamında değerlendirilmesi. Süleyman Demirel Üniversitesi Ziraat Fakültesi Dergisi 5(2): 1-8

Güre M, Özel M E\& Özcan H (2009). CORINE Arazi kullanımı sınıflandırma sistemine göre Çanakkale ili. Harran Üniversitesi Ziraat Fakültesi Dergisi 13(3): $37-48$

RG (2004). Su Kirliliği Kontrolü Yönetmeliği, Resmi Gazete Tarihi: 31.12.2004 Resmi Gazete Say1s1: 25687.

Vural H, Dinç U \& Öztürk N (1997). Sayısal uydu verileri yardımıyla arazi kullanım haritaları hazırlanmasının Doğu Akdeniz örneğinde araştırılması. III. Uzaktan Algllama ve Türkiye'deki Uygulamaları Semineri, 16-18 Mayıs Uludağ-Bursa, s. 1-6 